University of Nebraska - Lincoln

DigitalCommons@University of Nebraska - Lincoln

\title{
Integrating Remote Sensing and Geographic Information Systems
}

James W. Merchant

University of Nebraska-Lincoln, jmerchant1@unl.edu

Sunil Narumalani

University of Nebraska-Lincoln, snarumalani1@unl.edu

Follow this and additional works at: https://digitalcommons.unl.edu/natrespapers

Part of the Natural Resources and Conservation Commons

Merchant, James W. and Narumalani, Sunil, "Integrating Remote Sensing and Geographic Information Systems" (2009). Papers in Natural Resources. 216.

https://digitalcommons.unl.edu/natrespapers/216

This Article is brought to you for free and open access by the Natural Resources, School of at DigitalCommons@University of Nebraska - Lincoln. It has been accepted for inclusion in Papers in Natural Resources by an authorized administrator of DigitalCommons@University of Nebraska - Lincoln. 
Published in: The SAGE Handbook of Remote Sensing. 2009. SAGE Publications. 14 Apr. 2010. <http://www.sage-ereference.com/hdbk_remotesense/Article_n18.html>. Chapter DOI: 10.4135/978-1-8570-2105-9.n18

CHAPTER 18

\title{
Integrating Remote Sensing and Geographic Information Systems
}

\author{
James W. Merchant and Sunil Narumalani
}

\begin{abstract}
James W. Merchant is Professor in the School of Natural Resources, University of Nebraska-Lincoln (UNL) and is Director of UNL's Center for Advanced Land Management Information Technologies (CALMIT). Dr. Merchant received a B.A. in geography from Towson University, Baltimore, Maryland, and both the M.A. and Ph.D. in geography from the University of Kansas. His research has focused upon (1) development of strategies for large-area land cover characterization using digital multispectral satellite data, (2) spatial and contextual analysis of digital images, and (3) applications of geographic information systems in management of natural resources. Dr. Merchant was recipient of the 1999 Outstanding Contributions Award presented by the Nebraska GIS/LIS Association and the 1998 Outstanding Achievements Award conferred by the Remote Sensing Specialty Group of the Association of American Geographers. In 1997 he was honored with the John Wesley Powell Award that recognizes significant achievements in contributing to the research of the US Geological Survey. From 2000-2007 Dr. Merchant served as Editor of Photogrammetric Engineering and Remote Sensing, the journal of the American Society for Photogrammetry and Remote Sensing (ASPRS).
\end{abstract}

Sunil Narumalani is a Professor in the School of Natural Resources, and Associate Director of the Center for Advanced Land Management Information Technologies (CALMIT), University of Nebraska, Lincoln (UNL). He received his Ph.D. in geography from the University of South Carolina in 1993. Dr. Narumalani teaches courses in remote sensing (digital image analysis), introductory and advanced geographic information systems. His research focuses on the use of remote sensing for the extraction of biophysical information from satellite data and aircraft multispectral scanner systems, integration of geospatial data sets for ecological and natural resources mapping and monitoring, and the development of new image analyses techniques. Some of Dr. Narumalani's recent research has been on using remote sensing and GIS for the assessment of coral reefs and seagrasses off the coast of Florida and in the Caribbean. Over the past several years he has also been involved with projects pertaining to homeland security and military applications of geospatial technologies including the development of workshops for military intelligence units, integration of geospatial technologies for the National Guard, and initiating operational geographic databases for the Nebraska Emergency Management Agency (NEMA). Dr. Narumalani is also the Geography Program Coordinator at UNL.

Keywords: data integration, geospatial data fusion, image understanding, image processing.

\section{INTRODUCTION}

Remote sensing and geographic information systems (GIS) comprise the two major components of geographic information science (GISci), an overarching field of endeavor that also encompasses global positioning systems (GPS) technology, geodesy and 
traditional cartography (Goodchild 1992, Estes and Star 1993, Hepner et al. 2005). Although remote sensing and GIS developed quasi-independently, the synergism between them has become increasingly apparent (Aronoff 2005). Today, GIS software almost always includes tools for display and analysis of images, and image processing software commonly contains options for analyzing 'ancillary' geospatial data (Faust 1998). The significant progress made in 'integration' of remote sensing and GIS has been well-summarized in several reviews (Ehlers 1990, Mace 1991, Hinton 1996, Wilkinson 1996). Nevertheless, advances are so rapid that periodic reassessment of the state-of-theart is clearly warranted.

In this chapter, we focus on integration of remote sensing and GIS. Our definition of integration includes the use of each technology to benefit the other, as well as the application of both technologies, in concert, for modeling and decision-support. The discussion will range from consideration of simple visualization to data extraction and database development, and analyses based on 'multisource' data. We will, throughout, emphasize that, although progress in remote sensing-GIS integration has clearly benefited from advances in computing (hardware and software) and global positioning system (GPS) technology, equally important have been developments in theory and analytical methods, including innovations in use of decision trees, neural networks, and evidential reasoning. Finally, we will provide a look to the future and issues yet to be adequately addressed.

\section{Historical perspective}

Although the literature on remote sensing-GIS integration is relatively recent, the precursors of integration extend back to the early twentieth century. Aerial stereoscopic photography and analogue photogrammetric analysis methods have been routinely used since the 1930s to produce topographic maps, soils surveys, and land use maps. The digitized versions of such maps, of course, comprise key databases in today's geographic information systems. Modern digital aerial and satellite-borne remote sensing systems, and data analysis procedures such as digital photogrammetry and image classification, continue to be important means by which data for GIS are acquired, updated, and enhanced.

Likewise, persons engaged in interpreting aerial photography have recognized for at least 80 years that data from other sources, collateral or 'ancillary data' such as maps portraying topography, are critical in such work (see Estes et al. 1983, Jensen 2005). Photo interpretation demands the application of reasoning and logic, based on use of multiple data sources and formalized using aids such as interpretation keys (Campbell 1978, 2007, Estes et al. 1983). In recent decades, there have been many efforts to implement, and improve upon, strategies and methods for image analysis developed 
during the pre-digital era. Advances in digital remote sensing systems and data conversion (e.g., digitizing maps) have, for example, dramatically increased both the number and variety of geospatial datasets available, and strides in computing have greatly enhanced capabilities for processing and analyzing such data.

\section{Contemporary approaches to integration of remote sensing and GIS}

Ehlers (1990) provided a three-level taxonomy within which to consider the current state-of-the-art of remote sensing-GIS integration (Table 18.1). Most of the work we discuss in this chapter can be categorized as first-level or second-level integration, but progress toward the third-level is being made.

Gao (2002) points out that Ehlers' three-level classification must today be augmented to include GPS. The linear, interactive, hierarchical, and complex models of GPS-GIS-remote sensing integration he presents emphasize the directionality and sophistication of data flow between the three technologies, and in some respects parallel Ehlers' classification (i.e., trending toward 'seamless' integration that facilitates complex analyses). Although we will infrequently discuss GPS in the following pages, it should be understood that GPS is an essential component of contemporary GIS-remote sensing integration and is often employed in studies cited. Indeed, all of the geographic information science technologies constitute important components of an increasingly unified geospatial information analysis infrastructure trending toward Ehlers' thirdlevel.

An example of first-level integration of remote sensing and GIS is the overlay of a digital image (e.g., a digital orthophoto) with a cartographic dataset derived from a GIS (e.g., roads selected from a digital line graph), producing a merged product that allows an analyst to visualize information derived from both. It is assumed that the two datasets complement one another in some fashion. For instance, if the image is more recent than the GIS data, the analyst might commonly use information extracted from the image, through photo interpretation and 'heads-up' digitizing, to update the cartographic (e.g., roads) dataset. Similarly, a 'perspective view' of a landscape can be created by 'draping' an image over a three dimensional rendering of topography derived from a digital elevation model (DEM) manipulated in a GIS, thus enabling one to visualize associations between land cover (depicted on the image) and terrain configuration. Such products may be animated to produce virtual 'fly-overs' (see NASA's Scientific Visualization Studio for good examples - http://svs.gsfc.nasa.gov). 
Table 18.1 Levels of remote sensing-GIS integration (modified from Ehlers 1990)

\begin{tabular}{|c|c|c|}
\hline Level of integration & Principal characteristics & Examples of analyses supported \\
\hline First-level integration & $\begin{array}{l}\text { Achieved via data exchange } \\
\text { between separate GIS and } \\
\text { image analysis systems }\end{array}$ & $\begin{array}{l}\text { (a) Simultaneous display of GIS (usually vector) data and } \\
\text { remotely-sensed (raster) images; } \\
\text { (b) Ability to move the results of low-level image } \\
\text { processing to the GIS and the results of GIS-based } \\
\text { analyses to image-analysis software. }\end{array}$ \\
\hline Second-level integration & $\begin{array}{l}\text { Permits 'seamless' tandem or } \\
\text { combined raster-vector } \\
\text { processing facilitated by a } \\
\text { common user interface }\end{array}$ & $\begin{array}{l}\text { (a) Capability to incorporate GIS data directly into image } \\
\text { processing: } \\
\text { (b) Ability to accommodate heterogeneous data input in } \\
\text { a coherent manner; } \\
\text { (c) Ability to generate simulations combining a GIS and } \\
\text { image data with temporal evolution. }\end{array}$ \\
\hline Third-level integration & $\begin{array}{l}\text { Remote sensing and GIS operate } \\
\text { as a single, integrated } \\
\text { system - 'telegeoprocessing' }\end{array}$ & $\begin{array}{l}\text { (a) Accommodate raster and vector data in a unified } \\
\text { data structure; } \\
\text { (b) Facilitate real time analysis using sensor networks } \\
\text { and linkages to other technologies. }\end{array}$ \\
\hline
\end{tabular}

It is noteworthy that even relatively simple integration of remote sensing and GIS, such as the examples noted above, can be quite powerful. Visualization of integrated datasets may, for example, lead one to new insights and hypotheses regarding interrelationships between geospatial variables. Today, however, it is common to encounter instances of remote sensing-GIS integration that are far more complex than visualization. In the next sections of this chapter, we emphasize second-level and thirdlevel integration, first summarizing, respectively, ways in which data acquired via remote sensing are commonly used in GIS, and the importance of GIS (geospatial) data and analytical methods in remote sensing. In the course of this discussion we illuminate more sophisticated modes of integration encapsulated by current terminology such as 'multisource analysis,' 'data fusion,' and 'evidential reasoning.' Attention is also given to recent developments in sensor networks and 'telegeoprocessing.'

\section{INTEGRATION OF DATA DERIVED FROM REMOTE SENSING IN GIS}

As noted above, aerial photography has long been used to generate analogue geospatial products that, now, in a digital form, often constitute important components of GIS databases. With the advent of digital remote sensing systems and image processing software, the importance of remote sensing in GIS has expanded considerably. Applications of remote sensing range from the use of orthoimagery as a GIS base layer, to the development of thematic data on land use and the generation of unique geospatial datasets via extraction of cartographic features such as buildings and roads from imagery. 


\section{Orthoimagery as base data for GIS}

In a GIS database, all features must be positioned as accurately as possible. Additionally, all data layers must be registered to one another and should be georeferenced to a specific map projection and coordinate system. Base maps provide the frame-of-reference for positioning, registration and geo-referencing. In recent years, orthoimages generated from aerial photography (i.e., digital orthophotos) or fine spatial resolution satellite data have been used as base layers with increasing frequency (Davis and Wang 2003). Such images have been corrected to remove spatial displacements arising from sensor perspective and topographic relief. Orthoimages offer several advantages over products such as digitized USGS 7.5 quadrangles ('digital raster graphics') traditionally used as base maps. They are, for example, usually quite recent and they provide a 'realistic' view of the landscape with recognizable features being easily discerned (e.g., road intersections, buildings).

\section{Developing thematic data for GIS}

Remote sensing is the primary source for many kinds of thematic data critical to GIS analyses, including data on land use and land cover characteristics and surface elevation. Aerial and satellite imagery are also often used to assess landscape change and to update existing geospatial databases (e.g., roads, hydrography). Detailson methods used to create geospatial data from remote sensing are found throughout this volume. Here we highlight just a few examples of thematic geospatial data commonly derived via remote sensing.

\section{Surface elevation}

DEMs (Deng, in this volume) are widely used in GIS. As noted above, photogrammetry has long been the principal means by which surface elevation is mapped. Although aerial photography is still often used in such work, satellite imagery such as that acquired by IKONOS and ASTER is increasingly competitive in terms of resolution and accuracy (Hirano et al. 2003). Increasingly, active remote sensing methods that use lasers (airborne laser scanning (ALS) or LIDAR (Hyyppä et al., in this volume)) or microwave energy (IFSAR or InSAR (Kellndorfer and McDonald, in this volume)) are also being employed for producing DEMs (Hodgson et al. 2003). LIDAR data, for example, have been used to prepare DEMs with less than $30-\mathrm{cm}$ resolution, especially important for GIS-based flood risk assessment and transportation planning (Post et al. 2000). IFSAR provides unique cloud penetration, day/night operation and wide-area coverage. Shuttle Radar Topography Mission (SRTM) IFSAR data are being used to 
produce GTOPO30, a DEM having a 30 arc-second resolution that covers most of the earth's land areas (Gesch et al. 2001; http://www2.jpl.nasa.gov/srtm/).

\section{Land use and land cover mapping}

Campbell (2007) and Jensen (2005) provide excellent summaries of the state-of-the-art in mapping the type and condition of land use and land cover via multispectral image classification. As an example, the U.S. National Land Cover Dataset (NLCD), widely used in GIS analyses, was based primarily on classification of Landsat imagery (Homer et al. 2004; http:/ / www.mrlc.gov/ mrlc2k_nlcd.asp). Many advances in land use and land cover mapping are stemming from new methods of analysis founded on integration of remote sensing and ancillary GIS data, as described later in this chapter.

\section{Biophysical phenomena}

Remote sensing can also be used to provide unique thematic data regarding a variety of biophysical characteristics, including surface temperature, imperviousness, water clarity, evapotranspiration, vegetation pigments, biomass, canopy structure and height, leaf area index (LAI), and soil moisture (see Wulder 1998, Yang et al. 2003, Courault et al. 2005, Jensen 2005). Such data are required for GIS-based hydrologic, meteorological, wildfire risk, and crop simulation modeling (e.g., Keane et al. 2001, Nemani et al. 2002). Biophysical data derived from sensors such as MODIS are increasingly key inputs to global scale biophysical models focused on carbon dynamics, ecosystem processes, vegetation productivity, and oceanic phytoplankton distribution (Huete 2005).

\section{Feature extraction}

Feature extraction procedures are used to automate identification and mapping of physical objects (e.g., buildings, roads) from imagery collected by remote sensing. These procedures have been used to update, or increase accuracy of, existing GIS databases, or to create new data layers (Gruen and Li 1997). Mena (2003) reviewed current capabilities to automatically extract roads from aerial and satellite imagery. Shan and Lee (2005) reported on procedures to develop databases of buildings with IKONOS imagery. Hu et al. (2003) surveyed a suite of integrated remote sensing techniques that are being used for 3-D feature extraction in urban areas. 


\section{Landscape change}

Remote sensing provides many opportunities to identify and map changes in geospatial features (Lu et al. 2004, Jensen 2005). Today, aerial and satellite remote sensing are often used for updating GIS databases on land use, hydrography and transportation networks (e.g., Jensen et al. 1993, Laliberte et al. 2001). Impacts of natural hazards such as hurricanes, and progression of dynamic processes such as soil erosion, can also be assessed with remote sensing (e.g., Lupo et al. 2001). Multitemporal data are used to monitor seasonal and interannual landscape events at local, regional, and global scales. For example, Zhang et al. (2006) described use of MODIS data for assessing global patterns of vegetation greenness.

\section{USING GEOSPATIAL DATA AND GIS IN REMOTE SENSING}

Geospatial datasets depicting phenomena such as surface elevation, soils, transportation, hydrography, and land use are common components of geographic information systems. Although, as noted above, such datasets are frequently developed, at least in part, through analyses of aerial and satellite imagery, from a remote sensing point-of-view they are usually considered 'ancillary data.' The value of ancillary data in photo interpretation and digital image analysis is widely recognized (Tso and Mather 2001, Jensen 2005, Campbell 2007). Digital elevation models have been used particularly often in such work (see Florinsky 1998). Jensen (2005) notes that ancillary data may also include outputs of GIS analysis such as topographic slope and aspect (derived from a DEM), soils recoded into hydric and non-hydric classes, or polygons defining proximity to roads or streams (see Lunetta et al. 2003). Here we examine three ways in which ancillary (GIS) data are, today, frequently used in remote sensing: (1) geometric correction and orthorectification of imagery, (2) radiometric correction, and (3) image classification. All examples represent cases of Ehlers' (1990) 'second-level' integration.

\section{Geometric correction and orthorectification}

Images acquired via remote sensing exhibit spatial displacements of objects and scale variations that stem principally from sensor orientation and topographic relief (Aronoff 2005, Jensen 2007). Such displacements must be removed in order to create a planimetrically-correct ('orthorectified') image, i.e., an image that has properties similar to a map, such as consistent scale. Software for creating digital orthoimages is a component of many image analysis systems, but data required for rectification, 
including geodetic control (often obtained via GPS) and digital elevation data, must typically be imported from a GIS. The output of rectification, an orthoimage, is then often exported back to the GIS to support subsequent analyses. Orthoimages, as noted above, are now frequently used as base maps for registering and geo-referencing other layers in a GIS (Aronoff 2005). Geometric correction and registration are prerequisites to 'fusion' of multi-source data required for creation of products such as perspective views (Toutin 2004).

Orthoimages created from fine spatial resolution $(\sim 1 \mathrm{~m})$ sensors on satellites such as IKONOS and Quickbird have become more widely available in recent years. The quality of orthoimage products is closely related to the availability of accurate digital elevation models having horizontal and vertical resolution appropriate to the sensor (Toutin 2004). As discussed earlier, much current effort focuses on development of improved DEMs. LIDAR, for example, promises to provide a means of dealing with problems related to tall structures (e.g., buildings in urban areas), the presence of which can introduce errors in orthoimages generated from DEMs that ordinarily portray only 'bare earth' topography (Zhou et al. 2004).

\section{Radiometric correction}

Digital elevation models are also often used in radiometric correction of digital images (Tso and Mather 2001, Aronoff 2005, Jensen 2005). Spectral reflectance from the earth's surface is a complex function of land cover, angle of solar illumination, atmospheric condition, and topographic position (slope and aspect). In a given image, the brightness values for pixels of the same land cover type can vary substantially depending on whether they are situated in full sunlight (e.g., south facing slopes in the northern hemisphere) or shadow. These effects are especially evident in areas of high relief. If such artifacts are not removed they can significantly degrade results of multispectral classification.

Image processing designed to remove (or reduce) brightness variation stemming from topographic position is called 'topographic normalization' or 'terrain correction.' Topographic normalization is sometimes accomplished using simple band ratios that tend to compensate somewhat for reflectance differences, but more robust methods require the use of a DEM and GIS-derived slope and aspect (Gu et al. 1999, Riaño et al. 2003). As with geometric correction, the success of terrain correction depends a great deal on the availability of sufficiently fine resolution and accurate DEMs. 


\section{Image classification}

Although both the generation of orthoimagery and topographic normalization demonstrate a form of remote sensing-GIS integration, we currently see the most sophisticated types of integration manifested in digital image classification and modeling. The principal goal of such work is to enhance information extraction and thematic mapping by means of 'data fusion' and 'multisource analysis.' Enhancement usually entails improving the accuracy and/or categorical resolution of products traditionally generated solely from multispectral analysis of digital aerial or satellite imagery. Hutchinson (1982) provided an early, but still quite relevant, assessment of the use of multisource data in image classification. Excellent, more current, overviews are found in Campbell (2007), Jensen (2005), Jensen et al. (in this volume), Tso and Mather (2001), and Richards and Jia (1999).

A wide variety of methods for employing multi-source data in digital image classification have been developed. All may be viewed as attempts to exploit the longrecognized value of bringing to bear multiple sources of data (ancillary data and/or multiple types of imagery) on extraction of information from images (e.g., through image interpretation) and to invoke, to some extent, the reasoning and logic employed for most of a century in visual interpretation of images (see Jensen 2005, 2007, Campbell 2007). Hallmarks of image interpretation logic include (1) use of a systematic strategy that proceeds from 'knowns' to 'unknowns,' and (2) use of inference and 'convergence of evidence' exploiting observed relationships between multiple data types (image and ancillary data). The process of image interpretation often involves use of heuristics and/or 'rules' based on expert knowledge and observation (e.g., rules about biogeographic relationships between vegetation zonation, elevation, slope, and aspect in mountainous areas) (Campbell 1978, 2007, Estes et al. 1983). Here, we examine several approaches to integrating GIS with remote sensing to improve extraction of information from digital images. These include image stratification, classification modification, postclassification sorting, and advanced methods for multisource data analysis.

\section{Image stratification}

Stratification is a procedure for subdividing an image into regions ('strata') that are each considered 'internally homogeneous.' In digital image analysis, one approach is to use geospatial data for stratification and to subsequently classify each stratum separately. For example, Homer et al. (1997) used a GIS ecoregions dataset to stratify Landsat TM data for classification of land cover in Utah. Taking a different tack, Smith and Fuller (2001) used a digital map of agricultural field parcel boundaries to stratify Landsat TM, SPOT HRV and IRS imagery (see also Mason et al. 1988). Classification of land cover 
(e.g., crops) was subsequently carried out using a per-field or 'object-based' (as opposed to per-pixel) approach. The resulting maps were both more accurate and cleaner (exhibiting less visual noise) than a conventionally-produced per-pixel classification. GIS-assisted stratification has also been used as a guide for selecting training data for use in supervised classification (e.g., see Hutchinson 1982, Ortiz et al. 1997, Mesev 1998).

\section{Classification modification}

Most image classification relies on use of parametric supervised or unsupervised statistical techniques (Jensen 2005). A number of investigators have developed methods by which ancillary data can be integrated with imagery and used to improve multispectral classification. Ancillary geospatial data have, for example, sometimes been used to modify prior probabilities ('weights,' commonly assumed to be equal) in digital image classification using Bayesian Maximum Likelihood decision rules. GISderived data can be used to adjust prior probabilities to reflect frequencies with which informational classes are expected to occur in the image. Mesev (1998), for instance, showed that SPOT HRV classification of urban land cover could be improved by adjusting prior probabilities using GIS-derived census data (e.g., dwelling density).

Another approach has been to create, for each pixel, a 'stacked vector' comprised of both (multi) spectral image data and digital GIS data (a 'logical channel' such as elevation), in effect increasing the number of channels available for analysis and providing a means to incorporate nonspectral features (Maselli et al. 2000, Jensen 2005). For example, Wulder et al. (2004) used slope and aspect variables, derived in GIS from a DEM, and Landsat TM data to classify land cover in a mountainous area of British Columbia. They achieved the highest mapping accuracies using unsupervised classification of combined elevation and image data, after first stratifying the image into areas of shadow and nonshadow. Ricchetti (2000) found that slope, used as a logical channel, significantly improved Landsat TM classification of geological units.

Integrating GIS-derived data into image analysis can also be a means to improve class characterization and labeling of spectral classes. Ma et al. (2001), for example, used DEM-derived slope and aspect data in a two-stage 33-scene Landsat TM classification of Montana's land cover. They found that the approach improved both the efficiency of multiscene classification and robustness of class labeling. Focusing on agricultural land cover mapping, Ortiz et al. (1997) employed historical cropping pattern data in a GIS to assist in describing spectral classes developed through classification of multidate Landsat TM imagery. Hall et al. (2001) found that census data (e.g., population density and housing condition) integrated with Radarsat and Landsat TM imagery could be used to assess urban poverty in radios (census tracts) of Rosario, Argentina. 
Other researchers have selectively used ancillary geospatial data to add information to a traditional multispectral classification when conventional classification methods fail to adequately identify important 'information classes.' For instance, Vogelmann et al. (1998) merged National Wetlands Inventory (NWI) data into a Landsat TM classification of the Mid-Atlantic region to compensate for inability of a spectrally-based classifier to satisfactorily identify wetlands (see also Lunetta et al. 2003). Working with ERS-1 synthetic aperture radar imagery, Brivio et al. (2002) demonstrated that a DEMderived 'least accumulated cost-distance' dataset could be used to enhance maps of flooded areas when timing of image acquisition was suboptimal for the event.

\section{Postclassification class sorting}

It has long been observed that important land cover classes and conditions may be spectrally inseparable using conventional classification algorithms, and, conversely, that some spectral classes may need to be combined for cartographic purposes (Jensen 2005). For example, in areas of high relief, pixels representing water and coniferous forest in shadow may, inadvertently, be placed in the same spectral class because they exhibit similar reflectance. To a user of the product generated, this type of confusion is clearly undesirable. On the other hand, it is also common to find that pixels of one land cover type may be placed in several spectral classes because they represent subtle subclasses of the same cover type (e.g., Ponderosa Pine forest on different slopes and aspects). In this case, an analyst may wish to assemble pixels into a new combined informational class (e.g., Ponderosa Pine) for the final product.

Geospatial data can be used to help resolve such problems. Commonly this is accomplished with decision rules implemented through Boolean operations (IF-THEN-ELSE) to sort pixels from initial spectral classes into new 'informational classes' (Hutchinson 1982). For example, Cibula and Nyquist (1987) employed a DEM and climate data to increase categorical resolution of a Land-sat MSS classification of Olympic National Park from 9 to 21 classes, while maintaining an accuracy greater than $85 \%$ for most classes. Vogelmann et al. (1998) assembled elevation data (and derived slope, aspect, and shaded relief), Defense Meteorological Satellite Program city lights data, prior land use/land cover maps, digital line graphs, NWI data, and population census data to enhance an unsupervised Landsat TM-based land cover classification of the Mid-Atlantic region. Brown et al. (1993) used digitized ecoregions, major land resource areas, climate, and elevation data to enhance a land cover classification of the conterminous U.S. derived initially from multitemporal AVHRR NDVI imagery. An iterative spectral class splitting, merging and refinement procedure was implemented to produce 189 final informational classes from 70 initial spectral-temporal classes. Other good examples are reported by Harris and Ventura (1995), Mesev (1998), and Driese et al. (2001). 


\section{Advanced methods for multisource data analysis}

In recent years, a number of 'advanced methods' for image classification have been developed to augment, and potentially improve on, traditional statistically-based image classification procedures. These methods include rule-based or 'knowledge-based' classification ('expert systems'), artificial neural networks (ANN), decision tree classifiers and evidential reasoning (Lawrence and Wright 2001, Mertikas and Zervakis 2001, Jensen 2005, Jensen et al., in this volume;). Such approaches to data analysis lend themselves well to the integration of imagery with non-image (geospatial) data because, unlike traditional classification algorithms, they do not require assumptions regarding the normality of the data distribution, and they can readily accommodate heterogeneous data (discrete and continuous, numerical and categorical) that may have varying degrees of accuracy. In addition, these methods often facilitate structured, hierarchical strategies that mimic some aspects of human reasoning. Jensen (2005), Tso and Mather (2001) and Richards and Jia (1999) provide excellent introductions to advanced methods for multisource data analysis.

Rule-based classification methods employ a 'knowledge base' that stores facts, understandings, and heuristics specific to a particular domain (e.g., land cover classification based on IKONOS imagery and ancillary data). Rules and conditions, that draw on the knowledge base, guide classification (Jensen 2005). Huang and Jensen (1997) showed that a rule-based approach, using SPOT HRV data combined with terrain, soils and wind fetch data to classify land cover in the vicinity of a wetland, was superior to both conventional maximum likelihood and unsupervised classification. Their study employed decision tree classification, a procedure that involves systematic binary splitting of explanatory variables, such as spectral responses and ancillary data, to achieve specified classification goals. The decision tree method 'automatically' identifies critical variables, separating them from those less useful in classification, without extensive a priori expert knowledge (Campbell 2007). Homer et al. (2004) employed decision tree classification for development of the 2001 NLCD from multitemporal Landsat TM data and a variety of ancillary data (see http:/ / www.mrlc.gov/mrlc2k_nlcd.asp). Lawrence and Wright (2001) and Rogan et al. (2003) provide other good examples of the use of decision trees in integrated GIS-remote sensing analysis.

Rule-based classification can also be implemented through 'evidential reasoning' (Wilkinson 1996, Mertikas and Zervakis 2001). This procedure has many of the advantages of the decision tree approach, but also enables use of subjective judgment and provides the user with a measure of the risk (confidence) of the decision made for each class. Franklin et al. (2002), for instance, used evidential reasoning to map grizzly bear habitat in Alberta. Thirty-seven variables derived from Landsat TM imagery, a DEM, digital vegetation maps, and ecological unit maps were analyzed. Resulting maps 
were substantially better than those achieved by traditional maximum likelihood classification.

Artificial neural networks (ANN) constitute yet another method by which expert knowledge and ancillary data can be integrated with image analysis. An ANN is designed to simulate human reasoning and decision-making processes, including rule development through learning and adaptation based on training (Civco 1993, Foody 1995, Jensen 2005). Neural networks have sometimes been shown to perform well in comparison to traditional classification methods (see Bruzzone et al. 1997 and Mas 2004), but other investigators have found them less useful and more difficult to implement than other methods (Skidmore et al. 1997). Moreover, even when successfully used, it is sometimes difficult to explain how specific classification outcomes were achieved.

\section{INTEGRATION OF GPS, GIS, AND REMOTE SENSING}

The importance of GPS in contemporary GIS and remote sensing analyses can hardly be overstated (see Gao 2002). GPS may be employed at many different steps in analysis including image rectification, georeferencing thematic data in a GIS, collection of field data to support image analysis (e.g., for ground truth, calibration, or accuracy assessment), and development, or updating, of GIS databases portraying features such as roads and utilities. Although most instances of GPS-GIS- remote sensing integration continue to fall within Ehlers' (1990) first- and second-levels, the number of applications that demand the use of all three technologies in concert continues to expand. Examples

include work in precision farming, wildlife management, emergency response, and mobile mapping (see Gao 2002, Hong et al. 2006, Sampson and Delgiudice 2006).

\section{FUTURE PROSPECTS AND RESEARCH ISSUES}

We have reviewed a wide variety of ways in which GIS and remote sensing are integrated. The synergism between the two technologies has been clear for many years, and our appraisal follows in a long line of periodic assessments of the state-of-the-art and research challenges (e.g., Ehlers 1990, Mace 1991, Estes and Star 1993, Goodchild 1994, Hinton 1996, Wilkinson 1996, McMaster and Usery 2005). In recent decades 
theoretical and technical advances have fostered increasingly 'seamless' data analysis; nevertheless, in order for the full potential of remote sensing-GIS integration to be realized, significant, often inter-related, issues remain to be addressed.

\section{Advances in technology}

Geographic information science is a dynamic arena in which there are continual innovations. In remote sensing, for example, increasing use of hyperspectral and microwave sensors, LIDAR, very high resolution imagery, and time-series data present both opportunities (e.g., improved characterization of land cover) and challenges (e.g., handling large data volumes, image understanding) for data fusion and integrated data analysis (Hepner et al. 2005). Enhancements in internet, wireless and satellite communications, and innovations in in-situ sensors, are paving the way for increasingly robust 'real time' applications of remote sensing and GIS, a process some have termed 'telegeoprocessing' (Xue et al. 2002, Aksoy and Aksoy 2004). Web-based tools, such as Google Earth (http:/ / earth.google.com/) and Internet Map Service (IMS) applications, now provide an increasingly larger audience with ready access to geospatial data, and allow elementary integration of imagery and graphics, but more sophisticated implementation of web-based integrated geospatial analysis will require resolution of issues related to metadata standards, data transmission formats, client/server computation and communication protocols (Xue et al. 2002, Tsou 2004).

\section{Data availability and characteristics}

Geospatial datasets are more widely available, and less costly, than ever before. Webbased search tools and portals (e.g., http://gos2.geodata.gov/wps/ portal/gos and http:/ / nationalmap.gov/) provide increasingly efficient means to locate and access data. Yet, issues of identifying and characterizing varying, and often uncertain, data quality (e.g., spatial and categorical resolution, positional and attribute accuracy) remain to be resolved (Davis et al. 1991, Lunetta et al. 1991, Florinsky 1998, Shi et al. 2005; Zhu 2005). Moreover, traditional differences in the ways of representing geospatial data continue to present issues. Images in raster format must often be merged with GIS data in vector format, and outputs frequently are desired in vector format (for use in GIS-based analyses). Although strides are being taken toward development of new (e.g., object-oriented) geospatial data models, the long-standing dichotomy between raster and vector data structures (and 'field' and 'object' models of the world), and difficulties in integrating data represented in these disparate modes, remains problematic (Goodchild 1994, Blaschke et al. 2000). Recently, it has been 
recognized that refinement of ontologies that facilitate data integration may be critical to improving multisource data analysis (Fonseca et al. 2002).

\section{Analytical methods}

We have described, above, some 'advanced methods' of integrated data analysis that show substantial promise. However, building knowledge bases and establishing rules required to implement most such methods are difficult. Several investigators have explored use of data mining and machine learning procedures, although much remains to be accomplished (Huang and Jensen 1997, Yuan et al. 2005). Underpinning such efforts must be research designed to improve understanding of the human dimensions of geospatial/image data analysis, including, for example, articulation of the ways humans make decisions in image interpretation (Argialas and Harlow 1990). Additional progress is also needed in the use of fuzzy concepts to, for example, reduce artifacts of integrating data having differing formats (e.g., to better represent indeterminate boundaries such as gradients) and to improve multisource classification (Goodchild 1994, Jensen 2005). It is clear, too, that we require much better methods for tracking and characterizing errors generated when multisource data having different inherent scales, resolutions and accuracies are fused for analysis (Ehlers and Wenzhong 1996, Wilkinson 1996, Shi et al. 2005).

\section{Environmental modeling in a fully-integrated data processing environment}

The synergism between remote sensing and GIS is enhanced when these technologies are used in concert with ancillary technologies such as GPS and in-situ sensor networks and advanced telecommuncations. 'Telegeoprocessing' in concept embodies the thirdlevel integration envisioned by Ehlers (1990). Although, as noted above, many challenges remain, significant progress has been made toward this goal. Now we see increasing efforts to take the next step - full integration of telegeoprocessing with models designed to address specific issues and support decision-making. Keane et al. (2001), for example, review progress toward integration of remote sensing, GIS, and biophysical models for wildland fire risk assessment and management. Nemani et al. (2002) describe the Terrestrial Observation and Prediction System, a prototype endeavor that integrates satellite-derived data (e.g., MODIS LAI), ancillary geospatial data (e.g., DEM, soils), surface weather observations, and a terrestrial ecosystem model to forecast biophysical conditions such as soil moisture in near-real time. In applications of this type, integration of GIS and remote sensing is important in virtually the entire process from data capture and assimilation to database development, data analysis and delivery of information to users. As we approach realization of the potential of 
telegeoprocessing, the need to develop and test real-world applications will be a continuing priority.

\section{Education}

Finally, but certainly not least important, we believe that advances in integration of remote sensing and GIS call for periodic re-examination of how these technologies are taught (Lauer et al. 1991). At introductory and intermediate levels, instruction in remote sensing and GIS will likely continue to be offered in separate courses as has been traditional. However, the synergism between the two technologies is now quite evident, and technical means to integrate data are rapidly expanding. Next-generation geospatial scientists need to be conversant with both the intellectual foundations and the technical methods by which integrated data analysis can be conducted. We suggest that this might best be accomplished through capstone courses, practicums or seminars in which students are compelled to consider remote sensing-GIS integration and telegeoprocessing from the perspective of problem-solving rather than of the individual technologies.

\section{REFERENCES}

Aksoy, D. , and A. Aksoy , 2004. Satellite-linked sensor networks for planetary scale monitoring. http:/ / ieeexplore.ieee.org/ iel5/ 9623/ 30415/ 01404836.pdf (last accessed July 25 2007).

Argialas, D. P. and C. A. Harlow Computational image interpretation models: An overview and a perspective. Photogrammetric Engineering and Remote Sensing vol. 56 no. (6) pp. 871-886. 1990.

Aronoff, S. , 2005. Remote Sensing for GIS Managers. ESRI Press, Redlands, CA.

Blaschke, T. , S. Lang , E. Loup , J. Strobl , and P. Zeil , 2000. Object-oriented image processing in an integrated GIS/remote sensing environment and perspectives for environmental applications. In A. Cremers, ed. and K. Greve (eds), Environmental Information for Planning, Politics and the Public. Metropolis, Marlburg, Germany, pp. pp. 555-570.

Brivio, P. A. , R. Colombo , M. Maggi, and R. Tomasoni Integration of remote sensing data and GIS for accurate mapping of flooded areas. International Journal of Remote Sensing vol. 23 no. (3) pp. 429-441. 2002.

Brown, J. F. , T. R. Loveland, J. W. Merchant, B. C. Reed, and D. O. Ohlen Using multisource data in global land cover characterization: concepts, requirements and methods. Photogrammetric Engineering and Remote Sensing vol. 59 no. (6) pp. 977-987. 1993. 
Bruzzone, L. , C. Conese , F. Maselli, and F. Roli Multi-source classification of complex rural areas by statistical and neural-network approaches. Photogrammetric Engineering and Remote Sensing vol. 63 no. (5) pp. 523-533. 1997.

Campbell, J. B., Jr. A geographical analysis of image interpretation methods. The Professional Geographer vol. 30 no. (3) pp. 264-269. 1978.

Campbell, J. B. , 2007. Introduction to Remote Sensing (4th edn). The Guilford Press, New York, NY.

Cibula, W. G. and M. O. Nyquist Use of topographic and climatological models in a geographical data base to improve Landsat MSS classification for Olympic National Park. Photogrammetric Engineering and Remote Sensing vol. 53 no. (1) pp. 67-75. 1987.

Civco, D. L. Artificial neural networks for land-cover classification and mapping. International Journal of Geographical Information Systems vol. 7 no. (2) pp. 173-186. 1993.

Courault, D. , B. Seguin, and A. Olioso Review on estimation of evapotranspiration from remote sensing data: From empirical to numerical modeling approaches. Irrigation and Drainage Systems vol. 19 pp. 223-249. 2005.

Davis, C. H. and X. Wang Planimetric accuracy of IKONOS $1 \mathrm{~m}$ panchromatic orthoimage products and their utility for local government GIS basemap applications. International Journal of Remote Sensing vol. 24 no. (22) pp. 4267-4288. 2003.

Davis, F. W. , D. A. Quattrochi , M. K. Ridd, N. S-N. Lam , S. J. Walsh, J. C. Michaelsen , J. Franklin , D. A. Stow , C. J. Johannsen, and C. A. Johnston Environmental analysis using integrated GIS and remotely sensed data: some research needs and priorities. Photogrammetric Engineering and Remote Sensing vol. 57 no. (6) pp. 689-697. 1991.

Deng, Y. , in this volume. Making Sense of the Third Dimension Through Topographic Analysis. Chapter 22.

Driese, K. L. , W. A. Reiners, and R. C. Thurston Rule-based integration of remotely-sensed data and GIS for land cover mapping in NE Costa Rica. Geocarto International vol. 16 no. (1) pp. 35-44. 2001.

Ehlers, M. Remote sensing and geographic information systems: Towards integrated spatial information processing. IEEE Transactions on Geoscience and Remote Sensing vol. 28 no. (4) pp. 763-766. 1990.

Ehlers, M. and S. Wenzhong Error modelling for integrated GIS. Cartographica vol. 33 no. (1) pp. 11-21. 1996.

Estes J. E. and J. L. Star, 1993. Remote Sensing and GIS Integration: Towards a Prioritized Research Agenda Technical Report 93-4. National Center for Geographic Information and Analysis, Santa Barbara, CA. http:/ / www.ncgia.ucsb.edu/ Publications/ Tech_Reports/ 93/ 934.PDF (last accessed: March 21 2007).

Estes, J. E. , E. J. Hajic, and L. R. Tinney , 1983. Fundamentals of image analysis: Analysis of visible and thermal infrared data. In: D. Simonett (ed.), Manual of Remote Sensing. American Society for Photogrammetry and Remote Sensing, Bethesda, MD. Chapter 24: pp. 987-1124. 
Faust, N. , 1998. Raster GIS. In: T. W. Foresman (ed.), The History of Geographic Information Systems: Perspectives from the Pioneers. Prentice-Hall, Upper Saddle River, NJ. Chapter 5: pp. $59-72$.

Florinsky, I. V. Combined analysis of digital terrain models and remotely sensed data in landscape investigations . Progress in Physical Geography vol. 22 no. (1) pp. 33-60. 1998.

Fonseca, F. T. , M. J. Egenhofer, P. Agouris, and G. Camara Using ontologies for integrated geographic information systems. Transactions in GIS vol. 6 no. (3) pp. 231-257. 2002.

Foody, G. M. Land cover classification by an artificial neural network with ancillary information. International Journal of Geographical Information Systems vol. 9 no. (5) pp. 527-542. 1995.

Franklin, S. E. , D. R. Peddle , J. A. Dechka, and G. B. Stenhouse Evidential reasoning with Landsat TM, Dem and GIS data for landcover classification in support of grizzly bear habitat mapping. International Journal of Remote Sensing vol. 23 no. (21) pp. 4633-4652. 2002.

Gao, J. Integration of GPS with remote sensing and GIS: Reality and prospect. Photogrammetric Engineering and Remote Sensing vol. 68 no. (5) pp. 447-453. 2002.

Gesch, D. , J. Williams, and W. Miller A comparison of US Geological Survey seamless elevation models with Shuttle Radar Topography Mission data. Geoscience and Remote Sensing Symposium IGARSS '01 vol. 2 pp. 754-756. http:/ / ieeexplore.ieee.org/ iel5/ 7695/ 21046/ 00976625.pdf (last accessed: July 10 2007). 2001.

Goodchild, M. F. Geographical information science . International Journal of Geographical Information Systems vol. 6 no. (1) pp. 31-45. 1992.

Goodchild, M. F. Integrating GIS and remote sensing for vegetation analysis and modeling: methodological issues. Journal of Vegetation Science vol. 5 no. (5) pp. 615-626. 1994.

Gruen, A. and H. Li Semi-automatic linear feature extraction by dynamic programming and LSBSnakes. Photogrammetric Engineering and Remote Sensing vol. 63 no. (8) pp. 985-995. 1997.

Gu, D. , A. R. Gillespie , J. B. Adams, and R. Weeks A statistical approach for topographic correction of satellite images by using spatial context information. IEEE Transactions on Geoscience and Remote Sensing vol. 37 no. (1) pp. 236-246. 1999.

Hall, G. B. , N. W. Malcolm, and J. M. Piwowar Integration of remote sensing and GIS to detect pockets of urban poverty: the case of Rosario, Argentina. Transactions in GIS vol. 5 no. (3) pp. 235-253. 2001.

Harris, P. M. and S. J. Ventura The integration of geographic data with remotely-sensed imagery to improve classification in an urban area. Photogrammetric Engineering and Remote Sensing vol. 61 no. (8) pp. 993-998. 1995.

Hepner, G. F. , D. J. Wright, C. J. Merry , S. J. Anderson, and S. D. DeGloria , 2005. Remotely acquired data and information in GIScience. In: R. B. McMaster, ed. and E. L. Usery (eds), A Research Agenda for Geographic Information Science. CRC Press, Boca Raton, FL. Chapter 13: pp. 351-364.

Hinton, J. C. GIS and remote sensing integration for environmental applications. International Journal of Geographical Information Systems vol. 10 no. (7) pp. 877-890. 1996. 
Hirano, A. , R. Welch, and H. Lang Mapping from ASTER stereo image data: DEM validation and accuracy assessment. ISPRS Journal of Photogrammetry and Remote Sensing vol. 57 no. (5) pp. 356-370. 2003.

Hodgson, M. , J. R. Jensen, L. Schmidt, S. Schill, and B. Davis An evaluation of LIDAR- and IFSAR-derived digital elevation models in leaf-on conditions with USGS Level 1 and Level 2 DEMs. Remote Sensing of Environment vol. 84 pp. 295-308 2003.

Homer, C. , R. D. Ramsey, T. C. Edwards, Jr. , and A. Falconer Landscape cover-type modeling using a multiscene Thematic Mapper mosaic. Photogrammetric Engineering and Remote Sensing vol. 63 no. (1) pp. 59-67. 1997.

Homer C , C. Huang, L. Yang, B. Wylie, and M. Coan Development of a 2001 national land-cover database for the United States. Photogrammetric Engineering and Remote Sensing vol. 70 pp. 829840. 2004.

Hong, N. , J. G. White , R. Weisz , C. R. Crozier , M. L. Gumpertz, and D. K. Cassel Remote sensing-informed variable-rate nitrogen management of wheat and corn: Agronomic and groundwater outcomes. Agronomy Journal vol. 98 pp. 327-338. 2006.

$\mathrm{Hu}, \mathrm{J}$. , S. You, and U. Neumann Approaches to large-scale urban modelling. IEEE Computer Graphics and Applications vol. 23 no. (6) pp. 62-69. 2003.

Huang, X. and J. R. Jensen A machine-learning approach to automated knowledge-base building for remote sensing image analysis with GIS data. Photogrammetric Engineering and Remote Sensing vol. 63 no. (10) pp. 1185-1194. 1997.

Huete, A. R. , 2005. Global variability of terrestrial surface properties derived from MODIS visible to thermal-infrared measurements. IEEE 0-7803-9050-4-4/05. http:/ / ieeexplore.ieee.org/ iel5/ 10226/ 32601/ 01526782.pdf. (last accessed: March 19 2007).

Hutchinson, C. F. Techniques for combining Landsat and ancillary data for digital classification improvement. Photogrammetric Engineering and Remote Sensing vol. 48 no. (1) pp. 123-130. 1982.

Hyyppä, J. , W. Wagner , M. Hollaus, and H. Hyyppä , in this volume. Airborne Laser Scanning. Chapter 14.

Jensen, J. R. , 2005. Introductory Digital Image Processing: A Remote Sensing Perspective (3rd edn). Prentice-Hall, Upper Saddle River, NJ.

Jensen, J. R. , 2007. Remote Sensing of the Environment: An Earth Resource Perspective (2nd edn). Prentice-Hall, Upper Saddle River, NJ.

Jensen, J. R. , D. J. Cowen, J. D. Althausen, S. Narumalani, and O. Weatherbee An evaluation of the Coast-Watch change detection protocol in South Carolina. Photogrammetric Engineering and Remote Sensing vol. 59 no. (6) pp. 1039-1046. 1993.

Jensen, J. R. , J. Im , P. Hardin , and R. R. Jensen, in this volume. Image Classification. Chapter 19.

Keane, R. E. , R. Burgan, and J. van Wagtendonk Mapping wildland fuels for fire management across multiple scales: Integrating remote sensing, GIS, and biophysical modeling. International Journal of Wildland Fire vol. 10 pp. 301-319. 2001.

Kellndorfer, J. and K. McDonald, in this volume. Active and Passive Microwave Systems. Chapter 13. 
Laliberte, A. S. , D. E. Johnson, N. R. Harris, and G. M. Casady Stream change analysis using remote sensing and Geographic Information Systems (GIS). Journal of Range Management vol. 54 pp. A22-A50. 2001.

Lauer, D. T. , J. E. Estes, J. R. Jensen, and D. D. Greenlee Institutional issues affecting the integration and use of remotely sensed data and geographic information systems. Photogrammetric Engineering and Remote Sensing vol. 57 no. (6) pp. 647-654. 1991.

Lawrence, R. L. and A. Wright Rule-based classification systems using classification and regression tree (CART) analysis. Photogrammetric Engineering and Remote Sensing vol. 67 no. (10) pp. 1137-1142. 2001.

Lu, D. , P. Mausel , E. Brondĺzio , and E. Moran Change detection techniques. International Journal of Remote Sensing vol. 25 no. (12) pp. 2365-2407. 2004.

Lunetta, R. S. , R. G. Congalton, L. K. Fenstermaker , J. R. Jensen , K. C. McGwire, and L. R. Tinney Remote sensing and geographic information system data integration: error sources and research issues. Photogrammetric Engineering and Remote Sensing vol. 57 no. (6) pp. 677-687. 1991.

Lunetta, R. S. , J. Ediriwickrema , J. liames , D. M. Johnson , J. G. Lyon, A. McKerrow , and A. Pilant A quantitative assessment of a combined spectral and rule-based land-cover classification in the Neuse River Basin of North Carolina. Photogrammetric Engineering and Remote Sensing vol. 69 no. (3) pp. 299-310. 2003.

Lupo, F. , I. Reginster, and E. F. Lambin Monitoring land-cover changes in West Africa with SPOT Vegetation: impact of natural disasters in 1998-1999. International Journal of Remote Sensing vol. 22 no. (13) pp. 2633-2639. 2001.

Ma, Z. , M. M. Hart, and R. L. Redmond Mapping vegetation across large geographic areas: Integration of remote sensing and GIS to classify multisource data Photogrammetric Engineering and Remote Sensing vol. 67 no. (3) pp. 295-307. 2001.

Mace, T. H. (Guest Editor), ed. Special Issue: Integration of Remote Sensing and GIS. Photogrammetric Engineering and Remote Sensing vol. 57 no. (6) 1991.

Mas, J. F. Mapping land use/cover in a tropical coastal area using satellite sensor data, GIS and artificial neural networks. Estuarine, Coastal and Shelf Science vol. 59 no. (2) pp. 219-230. 2004.

Maselli, F. , A. Rodolfi , L. Bottai , S. Romanelli, and C. Conese Classification of Mediterranean vegetation by TM and ancillary data for the evaluation of fire risk. International Journal of Remote Sensing vol. 21 no. (17) pp. 3303-3313. 2000.

Mason, D. C. , D. G. Corr , A. Cross , D. C. Hogg , D. H. Lawrence , M. Petrou, and A. M. Tailor The use of digital map data in the segmentation and classification of remotely-sensed images . International Journal of Geographical Information Systems vol. 2 no. (3) pp. 192-215. 1988.

McMaster, R. B. and E. L. Usery (eds) 2005. A Research Agenda for Geographic Information Science. CRC Press, Boca Raton, FL.

Mena, J. B. State of the art on automatic road extraction for GIS update: a novel classification. Pattern Recognition Letters vol. 24 pp. 3037-3058. 2003.

Mertikas, P. and M. E. Zervakis Exemplifying the theory of evidence in remote sensing image classification. International Journal of Remote Sensing vol. 22 no. (6) pp. 1081-1095. 2001. 
Mesev, V. The use of census data in urban image classification. Photogrammetric Engineering and Remote Sensing vol. 64 no. (5) pp. 431-438. 1998.

Nemani, R. , P. Votava , J. Roads , M. White , S. Running, and J. Coughlan Terrestrial Observation and Prediction System: integration of satellite and surface weather observations with ecosystem models. Geoscience and Remote Sensing Symposium Proceedings, IGARSS '02 vol. 4 pp. 23942396. 2002.

Ortiz, M. J. , A. R. Formaggio, and J. C. N. Epiphanio Classification of croplands through integration of remote sensing, GIS and historical database. International Journal of Remote Sensing vol. 18 no. (1) pp. 95-105. 1997.

Post, J. L. , L. Borer, G. Priestnall , J. Jaafar, and A. Duncan Extracting urban features from LIDAR digital surface models. Computers, Environment and Urban Systems vol. 24 no. (2) pp. 65-78. 2000.

Riaño, D. , E. Chuvieco, J. Salas, and I. Aguado Assessment of different topographic corrections in Landsat-TM data for mapping vegetation types. IEEE Transactions on Geoscience and Remote Sensing vol. 41 no. (5) pp. 1056-1061. 2003.

Ricchetti, E. Multispectral satellite image and ancillary data integration for geological classification. Photogrammetric Engineering and Remote Sensing vol. 66 no. (4) pp. 429-435. 2000.

Richards, J. A. and X. Jia , 1999. Remote Sensing Digital Image Analysis: An Introduction (3rd edn). Springer, Berlin, Germany.

Rogan, J. , J. Miller, D. Stow , J. Franklin, L. Levien, and C. Fischer Land-cover change monitoring with classification trees using Landsat TM and ancillary data. Photogrammetric Engineering and Remote Sensing vol. 69 no. (7) pp. 793-804. 2003.

Sampson, B. A. and G. D. Delgiudice Tracking the rapid pace of GIS-related capabilities and their accessibility. Wildlife Society Bulletin vol. 34 pp. 1446-1454. 2006.

Shan, J. and S. D. Lee Quality of Building Extraction from IKONOS Imagery . Journal of Surveying Engineering vol. 131 no. (1) pp. 27-32. 2005.

Shi, W. Z. , M. Ehlers, and M. Molenaar Uncertainties in integrated remote sensing and GIS. International Journal of Remote Sensing vol. 26 pp. 2911-2915. 2005.

Skidmore, A. K. , B. J. Turner, W. Brinkhof, and E. Knowles Performance of a neural network: Mapping forests using GIS and remotely sensed data. Photogrammetric Engineering and Remote Sensing vol. 63 no. (5) pp. 501-514. 1997.

Smith, G. M. and R. M. Fuller An integrated approach to land cover classification: an example in the Island of Jersey. International Journal of Remote Sensing vol. 22 no. (16) pp. 3123-3142. 2001.

Toutin, T. Geometric processing of remote sensing images: Models, algorithms and methods. International Journal of Geographical Information Systems vol. 25 no. (10) pp. 1893-1924. 2004.

Tso, B. and P. M. Mather, 2001. Classification Methods for Remotely Sensed Data. Taylor and Francis, London, U.K.

Tsou, M.-H. Integrating web-based GIS and image processing tools for environmental monitoring and natural resource management. Journal of Geographical Systems vol. 6 pp. 155-174. 2004. 
Vogelmann J. E. , T. Sohl , S. M. Howard, and D. M. Shaw Regional land cover characterization using Landsat Thematic Mapper data and ancillary data sources. Environmental Monitoring and Assessment vol. 51 pp. 415-428. 1998.

Wilkinson, G. G. A review of current issues in the integration of GIS and remote sensing data . International Journal of Remote Sensing vol. 10 no. (1) pp. 85-101. 1996.

Wulder, M. Optical remote-sensing techniques for the assessment of forest inventory and biophysical parameters. Progress in Physical Geography vol. 22 no. (4) pp. 449-476. 1998.

Wulder, M. A. , S. E. Franklin, J. C. White, M. M. Cranny, and J. A. Dechka Inclusion of topographic variables in an unsupervised classification of satellite imagery. Canadian Journal of Remote Sensing vol. 30 no. (2) pp. 137-149. 2004.

Xue, Y. , A. P. Cracknell, and H. D. Guo Telegeo-processing: the integration of remote sensing, geographic information system (GIS), global positioning system (GPS) and telecommunication. International Journal of Remote Sensing vol. 23 no. (9) pp. 1851-1893. 2002.

Yang L. , C. Huang, C. Homer, B. Wylie, and M. Coan An approach for mapping large-area impervious surfaces: synergistic use of Landsat 7 ETM+ and high spatial resolution imagery. Canadian Journal of Remote Sensing vol. 29 pp. 230-240. 2003.

Yuan, M. , B. P. Buttenfield, M. N. Gahegan, and H. Miller, 2005. Geospatial data mining and knowledge discovery. In: R. B. McMaster, ed. and E. L. Usery (eds), A Research Agenda for Geographic Information Science. CRC Press, Boca Raton, FL. Chapter 14: pp. 365-388.

Zhang, X. , M. A. Friedl, and C. B. Schaaf Global vegetation phenology from Moderate Resolution Imaging Spectroradiometer (MODIS): Evaluation of global patterns. Journal of Geophysical Research vol. 111 pp. G04017 doi:10.1029/2006JG000217. 2006.

Zhou, G. , W. Schickler, A. Thorpe , P. Song, W. Chen, and C. Song True orthoimage generation in urban areas with very tall buildings. International Journal of Geographical Information Systems vol. 25 no. (22) pp. 5163-5180. 2004.

Zhu, A-X. , 2005. Research issues on uncertainty in geographic data and GIS-based analysis. In: R. B. McMaster, ed. and E. L. Usery (eds), A Research Agenda for Geographic Information Science. CRC Press, Boca Raton, FL. Chapter 7: pp. 197-223. 